\title{
Altered expression and loss of heterozygosity of the migration and invasion inhibitory protein $(M I I P)$ gene in breast cancer
}

\author{
FANGFANG SONG $^{1 *}$, LING ZHANG $^{1 *}$, PING JI $^{2}$, HONG ZHENG $^{1}$, \\ YANRUI ZHAO $^{1}$, WEI ZHANG ${ }^{2}$ and KEXIN CHEN $^{1}$ \\ ${ }^{1}$ Department of Epidemiology and Biostatistics, Key Laboratory of Breast Cancer Prevention and Therapy, \\ Ministry of Education, Key Laboratory of Cancer Prevention and Therapy, National Clinical Research Center for Cancer, \\ Tianjin Medical University Cancer Institute and Hospital, Tiyuan Bei, Hexi, Tianjin 300060, P.R. China; \\ ${ }^{2}$ Department of Pathology, The University of Texas MD Anderson Cancer Center, Houston, TX 77030, USA
}

Received November 20, 2014; Accepted January 9, 2015

DOI: 10.3892/or.2015.3905

\begin{abstract}
Previous studies have characterized the migration and invasion inhibitory protein (MIIP) as a novel putative tumor-suppressor gene that regulates cell migration and invasion as well as the mitotic checkpoint. The MIIP gene is located on chromosome $1 \mathrm{p} 36.22$, a common site for deletion in many solid tumors including breast cancer. In the present study, we evaluated MIIP expression and allelic deletion to gain insight into the role of the MIIP gene in breast cancer. $M I I P$ gene mRNA and protein expression was assessed in 86 matched breast cancer and adjacent normal tissues. Loss of heterogeneity $(\mathrm{LOH})$ of the MIIP gene was determined using single-nucleotide polymorphism (SNP) and microsatellite (MS) markers in 149 breast carcinomas and the corresponding normal lymphocytes. The analysis revealed that the expression levels of MIIP mRNA and protein were downregulated in tumor specimens compared to those in corresponding adjacent tissues. Advanced clinical stage and tumor size $>2 \mathrm{~cm}$ were associated with a decreased MIIP expression level. Twenty-six percent (37/142) of tumors were shown to have LOH at the MIIP locus by MS and SNP markers. Breast cancer patients
\end{abstract}

Correspondence to: Professor Kexin Chen, Department of Epidemiology and Biostatistics, Tianjin Medical University Cancer Institute and Hospital, Huanhu Xi Road, Tiyuan Bei, Hexi, Tianjin 300060, P.R. China

E-mail: chenkexin@tjmuch.com

${ }^{*}$ Contributed equally

Abbreviations: TSG, tumor-suppressor genes; MIIP, migration and invasion inhibitory protein; IIp45, invasion inhibitory protein 45; IGFBP2, insulin-like growth factor binding protein 2; SNP, singlenucleotide polymorphism; $\mathrm{LOH}$, loss of heterogeneity; ER, estrogen receptor; PR, progesterone receptor; MS, microsatellite; HDAC6, histone deacetylase 6

Key words: breast cancer, gene inactivation, LOH, MIIP, mitosis with LOH at the SNP marker rs2295283 experienced shorter survival time. The attenuated expression and LOH of the MIIP gene may contribute to the poor prognosis of breast cancer, supporting a tumor-suppressing role of MIIP gene in the pathogenesis of this disease.

\section{Introduction}

Breast cancer is the most common type of cancer among women worldwide, and its incidence is on the increase (1). Clearly identified genetic susceptibilities to early onset familial breast cancer are associated with mutations in tumor-suppressor genes (TSGs) BRCA1 and BRCA2, which, however, are not important in sporadic breast cancer (2). Evidence suggests that allelic loss at chromosome $1 \mathrm{p} 36$ is a common genetic event in a various types of human cancer including breast cancer, suggesting the presence of at least one TSG located in this region (3). One of these genes is p73 (1p36.33), a p53 homologue (4). However, the allelic status of other genes mapped to this chromosomal region has yet to be sufficiently elucidated.

The migration and invasion inhibitory protein (MIIP; or invasion inhibitory protein 45, IIp45) gene, located on chromosome 1p36.22, has emerged as a key gene that plays a critical role in tumorigenesis (5). MIIP was initially identified in a yeast two-hybrid screen for proteins that interact and inhibit insulin-like growth factor binding protein 2 (IGFBP2) (6). Advances in characterizing this protein have demonstrated that MIIP regulates cell migration and mitosis (7), two essential microtubule and cytoskeleton-associated processes for homeostasis of tissues and fetal development. Additionally, MIIP is underexpressed in human glioma, and an in vivo study using transgenic mouse models showed that exogenously introduced MIIP reduced the incidence and grade of glioma (8). For breast cancer, a case-control epidemiological study conducted by our team identified a functional genetic single-nucleotide polymorphism (SNP) of MIIP that is associated with the risk of breast cancer development and prognosis (9).

However, unlike the classical TSGs such as TP53, PTEN and $R b$, in which frequent mutations are identified in cancers, previous mutation screening among glioma and pancreatic cancer tissues only detected rare mutations in the MIIP 
gene $(6,10)$, similar to the low mutation frequency found in the $p 73$ gene in human cancers. Haploinsufficiency or loss of one allele in another group of TSGs has been described as an alternative important mechanism leading to gene inactivation and cancer development. Genes in this group include the $C H D 5$ gene on 1p36 and the PTEN gene on 10q23 $(11,12)$. In the present study, we evaluated loss of heterogeneity $(\mathrm{LOH})$ of the MIIP locus in breast cancers and investigated the expression of MIIP in breast cancer tissues by reverse-transcription-quantitative PCR (RT-PCR) and western blotting.

\section{Materials and methods}

Patient characteristics. All 149 patients enrolled in the present study were newly diagnosed and histologically confirmed breast cancer cases from the Breast Cancer Research Center in Tianjin Medical University Cancer Institute and Hospital (TMUCIH) from January 1, 2006 to June 1, 2008. The patients recruited in the present study had not received any chemoor radiotherapy prior to obtaining blood samples. The blood samples were obtained prior to surgery. All the patients met the following inclusion criteria: Tianjin residents aged $18-65$ years with no previous diagnosis of cancer. The Ethics Committee of TMUCIH approved the study protocol. Written informed consent was obtained from all the patients participating in the present study.

The participants were personally interviewed using a structured questionnaire regarding their socio-demographic characteristics, lifestyle, and family history of cancer. Clinical information on tumor features and disease severity, including morphology, tumor size, lymph node and organ metastasis, tumor stage, and estrogen and progesterone receptor (ER and PR) status was also collected. Each subject donated $20 \mathrm{ml}$ of blood, which was collected in heparinized tubes. Matched tumor and adjacent normal tissues from 86 cases were obtained from the Tissue Bank Facility of TMUCIH, which collects all solid tumor tissues from surgical patients when possible.

$R N A$ extraction and $R T-q P C R$. Total RNA were extracted and purified from the 86 pairs of snap-frozen breast cancer and adjacent normal tissues according to the protocol of TRIzol reagent (Invitrogen Corporation, Grand Island, NY, USA). The reverse-transcribed products, cDNA, were synthesized from $5.0 \mathrm{ng}$ total RNA in a $20 \mu \mathrm{l}$ reaction mixture using M-MLV reverse transcriptase (Invitrogen Life Technologies, Carlsbad, CA, USA). RT-qPCR was performed on ABI PRISM 7900 Fast Real-Time system (Applied Biosystems, Foster City, CA, USA) using TaqMan gene expression assay for human MIIP according to the manufacturer's instructions [Takara Biotechnology (Dalian) Co., Ltd., China]. The human $G A P D H$ housekeeping gene was measured as an endogenous control. The probe used was purchased from Applied Biosystems (Hs00976263_m1 for MIIP). Each PCR was performed in triplicate in a 5- $\mu 1$ reaction volume containing $100 \mathrm{ng}$ cDNA as template to detect MIIP gene expression. Amplification was performed under the following conditions: $50^{\circ} \mathrm{C}$ for $2 \mathrm{~min}$, then $95^{\circ} \mathrm{C}$ for $10 \mathrm{~min}$, followed by 40 cycles of denaturation at $95^{\circ} \mathrm{C}$ for $15 \mathrm{sec}$ and annealing/extension at $60^{\circ} \mathrm{C}$ for $1 \mathrm{~min}$. The 7900 Sequence Detection System 2.3 software (Applied Biosystems) was used to calculate the rela- tive fold-change in MIIP expression by the $2^{-\Delta \Delta \mathrm{Ct}}$ method with $95 \%$ confidence (13).

Protein extraction and western blotting. Approximately 100-150 mg frozen tissues were homogenized with pestle and mortar containing liquid nitrogen, and then dissolved in 500-1,000 $\mu 1$ lysis buffer (500 $\mu$ l protein lysate, $5 \mu$ DTT and $5 \mu \mathrm{l}$ protease inhibitor). Following incubation on ice for $15 \mathrm{~min}$, the resulting lysates were centrifuged at $140,000 \mathrm{x} \mathrm{g}$ for $15 \mathrm{~min}$ at $4^{\circ} \mathrm{C}$ in an ultracentrifuge. Supernatant fractions were collected on ice and the total protein concentration was measured according to the protocol of the BCA Protein Quantitative Detection kit (Sangon Biological Engineering Technology and Services Corporation, Shanghai, China). Twenty microliters supernatant ( 40-50 ng protein) was mixed with 5X SDS loading buffer containing $62.5 \mathrm{mM}$ Tris- $\mathrm{HCl}$, $\mathrm{pH} 6.8,4 \%$ SDS, $10 \%$ glycerol, $5 \% \beta$-mercaptoethanol and $0.1 \%$ bromophenol blue, and then boiled at $95^{\circ} \mathrm{C}$ for $5 \mathrm{~min}$. The denatured proteins of each group were loaded into lanes with 30\% SDS-polyacrylamide gel electrophoresis, and then transferred to nitrocellulose membrane. Blots were blocked with $5 \%$ skim milk at room temperature for $1 \mathrm{~h}$ and incubated overnight at $4^{\circ} \mathrm{C}$ with monoclonal rabbit anti-IIP45 antibody (1:800; Sigma-Aldrich, St. Louis, MO, USA) and then with HRP-conjugated goat anti-rabbit IgG (1:2,000; Santa Cruz Biotechnology, Inc., Dallas, TX, USA) as secondary antibody at room temperature for $1 \mathrm{~h}$. $\beta$-actin was used as an internal reference and the antibodies (mouse anti- $\beta$-actin antibody and the secondary HRP-linked goat anti-mouse IgG antibody) were purchased from Santa Cruz Biotechnology. Immunoreactive bands were visualized using the Immobilon ${ }^{\mathrm{TM}}$ Western Chemiluminescent HRP Substrate (Millipore Corporation, Billerica, MA, USA), and exposed to film. The bands were subjected to densitometric quantification by Image $\mathrm{J} 2 \mathrm{X}$ [National Institutes of Health (NIH), Bethesda, MD, USA].

DNA extraction and $\mathrm{LOH}$ analysis. $\mathrm{LOH}$ was determined on specific PCR products of tumors and corresponding normal peripheral leukocytes. Genomic DNA was extracted from paired snap-frozen tumor tissues and normal controls using the Qiagen DNA Mini kit according to the manufacturer's protocol (Axygen Biosciences, Union City, CA, USA). LOH analysis of the MIIP locus was performed using three microsatellite (MS) markers and one SNP marker on 149 human breast cancer tumors. Following a search in the Human Genome Annotation Database (UCSC) and Human Sequence Tag Map (NCBI), no MS marker intragenic to the MIIP gene was identified. The three nearest MS loci flanking the 5' and 3' side of the MIIP gene (within $0.2 \mathrm{Mb}$ of the gene): D1S2740,D1S489 and D1S434 were selected. PCR was performed with synthesized labeled primers (Sangon Biological Engineering Technology and Services Corporation; Table I) specific to the MS markers obtained from the NCBI UNISTAT database. The size of amplification products was determined by capillary electrophoresis on a 3730XL Genetic Analyzer (Applied Biosystems). Data were collected and analyzed by Gene-Scan3.1g software (Applied Biosystems).

An SNP with a high heterozygosity status present in the MIIP gene was selected from the Ensembl database (Table I). 
Table I. Details of the SNP and microsatellite markers used for detecting the LOH status of MIIP.

\begin{tabular}{|c|c|c|c|}
\hline Marker & Primer sequences $\left(5^{\prime}-3^{\prime}\right)$ & $\operatorname{Tm}\left({ }^{\circ} \mathrm{C}\right)$ & Product size $(\mathrm{bp})$ \\
\hline \multirow[t]{2}{*}{ rs2295283 } & Forward: CTCAGCCTAAATGCTCGCTA & & \\
\hline & Reverse: TGGCACGGTCAGAGAAACAA & 58 & 460 \\
\hline \multirow[t]{2}{*}{ D1S2740 } & Forward: AGCCTTTTGATACTCTTACTGTGG & & \\
\hline & Reverse: AAAGATTGGGAAGTGGCTCA & 55 & 201 \\
\hline \multirow[t]{2}{*}{ D1S489 } & Forward: AGCCAGACCAAGTCTCAACA & & \\
\hline & Reverse: ACAAAATGATGGGGTTATGG & 55 & $141-153$ \\
\hline \multirow[t]{2}{*}{ D1S434 } & Forward: AGCTAATTTACATTACCCAAAAAGA & & \\
\hline & Reverse: ACAATACAGCAGCAGGTGGC & 55 & 260 \\
\hline
\end{tabular}

MIIP, migration and invasion inhibitory protein; SNP, single-nucleotide polymorphism; LOH, loss of heterogeneity; Tm, temperature.

A

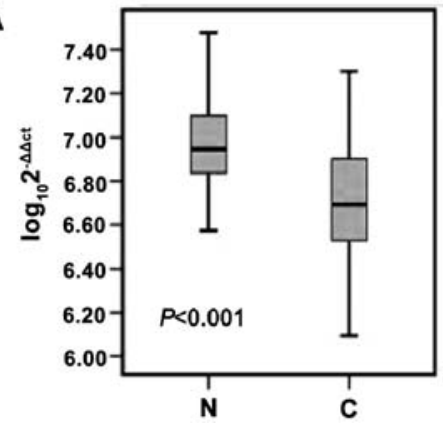

B

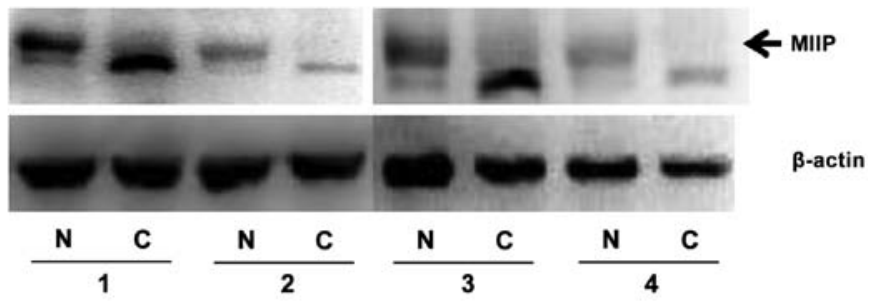

Figure 1. Decreased MIIP expression in breast cancer tissues. (A) MIIP mRNA expression in adjacent normal tissues (N) and (C) breast cancer tissues. (B) MIIP protein expression in representative adjacent normal tissues (N) and (C) breast cancer tissues. MIIP, migration and invasion inhibitory protein.

This functional SNP (rs2295283) has been found to be associated with risk and prognosis of breast cancer in a previous large-scale epidemiological study (9). Genotypic and allelic frequency of this SNP was conducted by using the MGB TaqMan probe assay (Applied Biosystems) as described previously (9).

For LOH analysis, only those sample pairs in which the normal lymphocyte DNA exhibited a heterozygous pattern, i.e., two alleles for each MS or SNP marker, were considered informative $(14,15)$. Among the informative sample pairs for MS loci, LOH was evaluated by comparing the areas of the two alleles in tumor tissue with corresponding peripheral leukocytes (15). An absence or a reduction by $>33 \%$ for one allele in the tumor DNA as compared to the normal DNA was interpreted as LOH (16). Concerning the SNP site, LOH in informative samples was defined as a total loss of one allele in tumor DNA compared to its normal tissue counterpart (14). For scoring changes, LOH frequency for each MS or SNP marker was calculated separately as a percentage of all the informative samples in that particular locus (14).

Statistical analysis. Statistical analysis was performed with the SPSS version 17.0. Statistical tests were two-sided, and a difference was considered statistically significant at $\mathrm{P}<0.05$. The relative expression levels of MIIP mRNA were quantified using the $2^{-\Delta \Delta \mathrm{Ct}}$ method, and the data were $\log _{10}$-transformed for analysis. Comparison of MIIP mRNA or protein expression level between tumors and adjacent normal tissues was made by the Wilcoxon rank-sum (Mann-Whitney) test. The $\chi^{2}$ test was employed to compare the differences in the frequency distribution of age, family history and clinical variables including morphology, tumor size, lymph node metastasis, tumor stage, and ER/PR status between cases with different LOH status in MIIP gene. MIIP mRNA (further divided into high- and low-expression groups by the median of $\log _{10} 2^{-\Delta \Delta \mathrm{Ct}}$ value) and protein expression were correlated with clinical characteristics and MIIP gene LOH status by using the $\chi^{2}$ and Wilcoxon tests. The correlation between survival (overall survival) and LOH status of the MIIP gene was analyzed using the Kaplan-Meier method and log-rank test.

\section{Results}

MIIP expression in breast cancer. We analyzed MIIP mRNA and protein expression in 86 cases with breast cancer and matched adjacent normal breast tissues. MIIP mRNA and protein expression was detected in all the adjacent normal tissues and in the majority of the breast carcinomas. The comparison between paired normal adjacent tissue and tumors revealed that $M I I P$ transcript expression was significantly decreased in carcinomas (Fig. 1A). On the basis of $\log _{10} 2^{-\Delta \Delta c t}$ value, tumors were divided into the high- or low-expression groups by the median expression level. We found that MIIP gene exhibited a descending expression pattern with an 
Table II. Correlation between clinicopathological characteristics and MIIP expression in 86 breast cancer cases.

\begin{tabular}{|c|c|c|c|c|}
\hline & mRNA expression & & Protein expression & \\
\hline Variables & High expression/total (\%) & P-value & Median (min-max) & P-value \\
\hline \multicolumn{5}{|l|}{ Age (years) } \\
\hline$\leq 50$ & 19/41 (46.34) & \multirow[t]{2}{*}{0.860} & $14.85(0.95-54.24)$ & \multirow[t]{2}{*}{0.465} \\
\hline$>50$ & $20 / 45(44.44)$ & & $20.05(0.96-63.45)$ & \\
\hline \multicolumn{5}{|l|}{ ER } \\
\hline- & $17 / 32(53.12)$ & \multirow[t]{2}{*}{0.265} & $21.19(1.68-63.45)$ & \multirow[t]{2}{*}{0.105} \\
\hline+ & $22 / 54(40.74)$ & & $14.85(0.95-63.04)$ & \\
\hline \multicolumn{5}{|l|}{ PR } \\
\hline- & 20/36 (55.56) & \multirow[t]{2}{*}{0.107} & $19.99(3.51-63.45)$ & \multirow[t]{2}{*}{0.956} \\
\hline+ & 19/50 (38.00) & & $16.61(0.95-63.04)$ & \\
\hline \multicolumn{5}{|c|}{ Benign breast disease } \\
\hline Never & $30 / 68(44.11)$ & \multirow[t]{2}{*}{0.656} & $16.61(0.96-63.45)$ & \multirow[t]{2}{*}{0.949} \\
\hline Ever & 9/18 (50.00) & & $18.09(0.95-40.06)$ & \\
\hline \multicolumn{5}{|c|}{ Family history of cancer } \\
\hline No & $27 / 58(46.55)$ & \multirow[t]{2}{*}{0.747} & $18.09(0.95-63.45)$ & \multirow[t]{2}{*}{0.214} \\
\hline Yes & $12 / 28(42.86)$ & & $14.98(0.96-63.04)$ & \\
\hline \multicolumn{5}{|l|}{ Morphology } \\
\hline Non-invasive & 29/57 (50.88) & \multirow[t]{2}{*}{0.149} & $16.61(0.96-63.45)$ & \multirow[t]{2}{*}{0.747} \\
\hline Invasive & $10 / 29(34.48)$ & & $17.17(0.95-63.04)$ & \\
\hline \multicolumn{5}{|l|}{ Clinical stage } \\
\hline 0 & $11 / 13(84.62)$ & \multirow[t]{4}{*}{0.012} & $15.85(3.51-63.04)$ & \multirow[t]{4}{*}{0.249} \\
\hline I & 13/34 (41.18) & & $19.45(1.01-63.45)$ & \\
\hline II & $14 / 36(38.89)$ & & $16.61(0.96-56.67)$ & \\
\hline III & 1/3 (33.33) & & $12.46(0.95-23.98)$ & \\
\hline \multicolumn{5}{|l|}{ Tumor size $(\mathrm{cm})$} \\
\hline$\leq 2$ & $14 / 19(73.68)$ & \multirow[t]{2}{*}{0.005} & $15.85(3.51-63.04)$ & \multirow[t]{2}{*}{0.289} \\
\hline$>2$ & 25/67 (37.31) & & $17.17(0.95-63.45)$ & \\
\hline \multicolumn{5}{|c|}{ Lymph node metastasis } \\
\hline No & $22 / 43(51.16)$ & \multirow[t]{2}{*}{0.279} & $18.78(1.01-63.45)$ & \multirow[t]{2}{*}{0.843} \\
\hline Yes & $17 / 43(39.53)$ & & $15.89(0.95-56.67)$ & \\
\hline
\end{tabular}

ER, estrogen receptor; PR, progesterone receptor; MIIP, migration and invasion inhibitory protein.

advanced TNM stage of the tumors $(\mathrm{P}=0.012)$ and with an increased tumor size $(\mathrm{P}=0.005)$ (Table II).

At the protein level, 86 cases were analyzed for MIIP expression by western blotting, which varied in the same manner to the transcriptional level with a lower MIIP expression in cancer tissues than the normal tissues (Fig. 1B). No significant difference was identified in the expression pattern of MIIP protein based on patient clinical characteristics, with the exception of TNM staging. Tumor tissues in the advanced stage (stage III) expressed significantly decreased MIIP levels than those in the early stages (stage 0, I and II): 16.99 (0.96-63.45) vs. 12.46 (0.95-23.98), $\mathrm{P}=0.043$.

LOH analysis of the MIIP locus. To determine the possible mechanism of MIIP gene underlying breast cancer onset and development, a LOH analysis with MS/SNP markers for MIIP gene was performed in 149 cases. The four MS and SNP markers used were all informative, being clearly biallelic in the normal lymphocyte samples and showing partial or total loss of one allele in the tumor samples (candidate LOH samples) or remained biallelic. Representative $\mathrm{LOH}$ profiles of all the markers used in the selected samples are shown in Fig. 2. As shown in Table III, of the 149 cancer tumors analyzed with the intragenic SNP marker rs2295283, 84 samples were informative (heterozygous), 9 of which $(10.71 \%)$ showed LOH. For the flanking MS loci, 138 of $149(92.62 \%)$ cancer samples were informative. LOH frequency affecting $\geq 1 \mathrm{MS}$ locus observed was $23.91 \%$ (33/138). The most frequently deleted loci were D1S489 (20/97, 20.62\%) and D1S2740 (14/70, 20.00\%), with LOH for D1S434 marker being similar, at $16.49 \%(16 / 97)$ in all the samples studied.

A comparison of the rates of $\mathrm{LOH}$ for the four MS/SNP markers in breast cancer patients with different subtypes of tumor characteristics demonstrated no correlations among the 

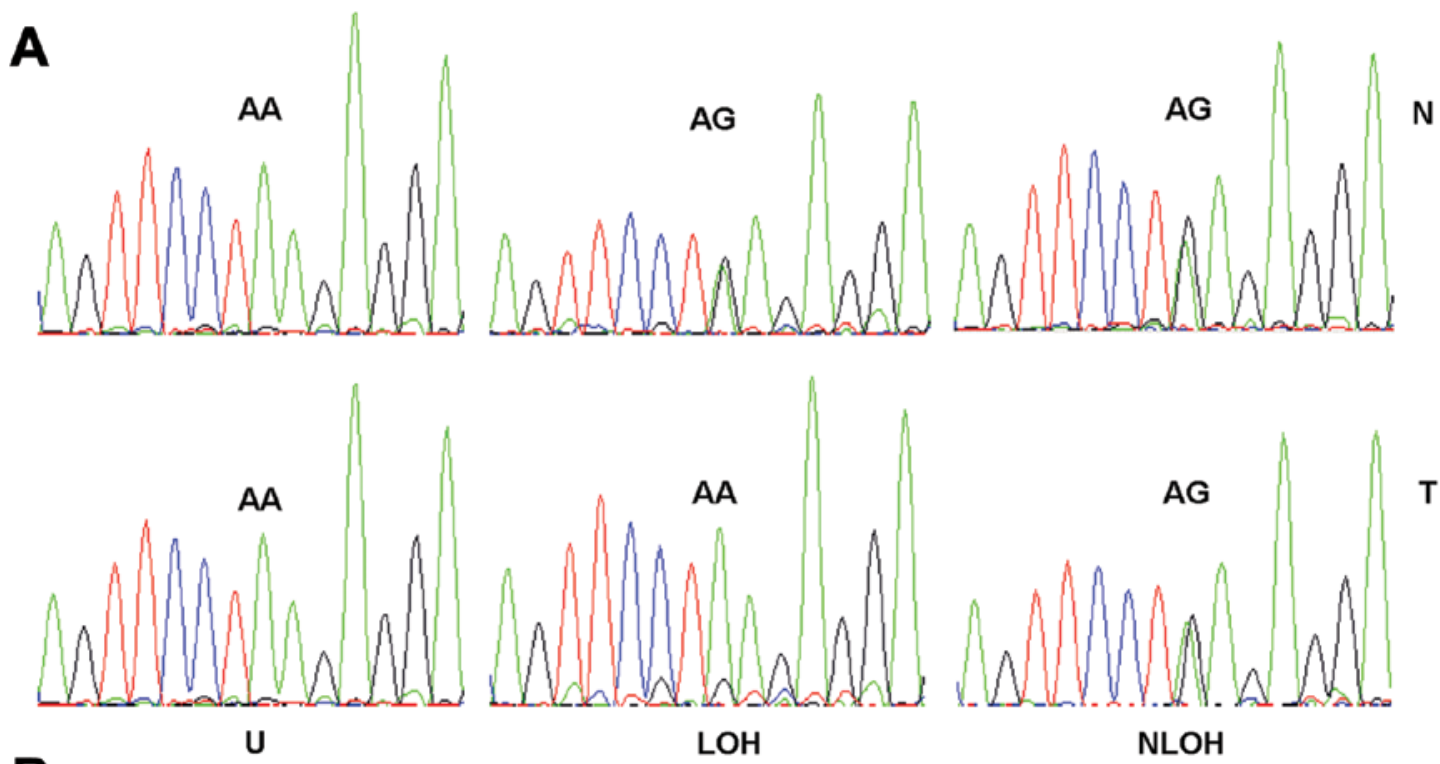

B
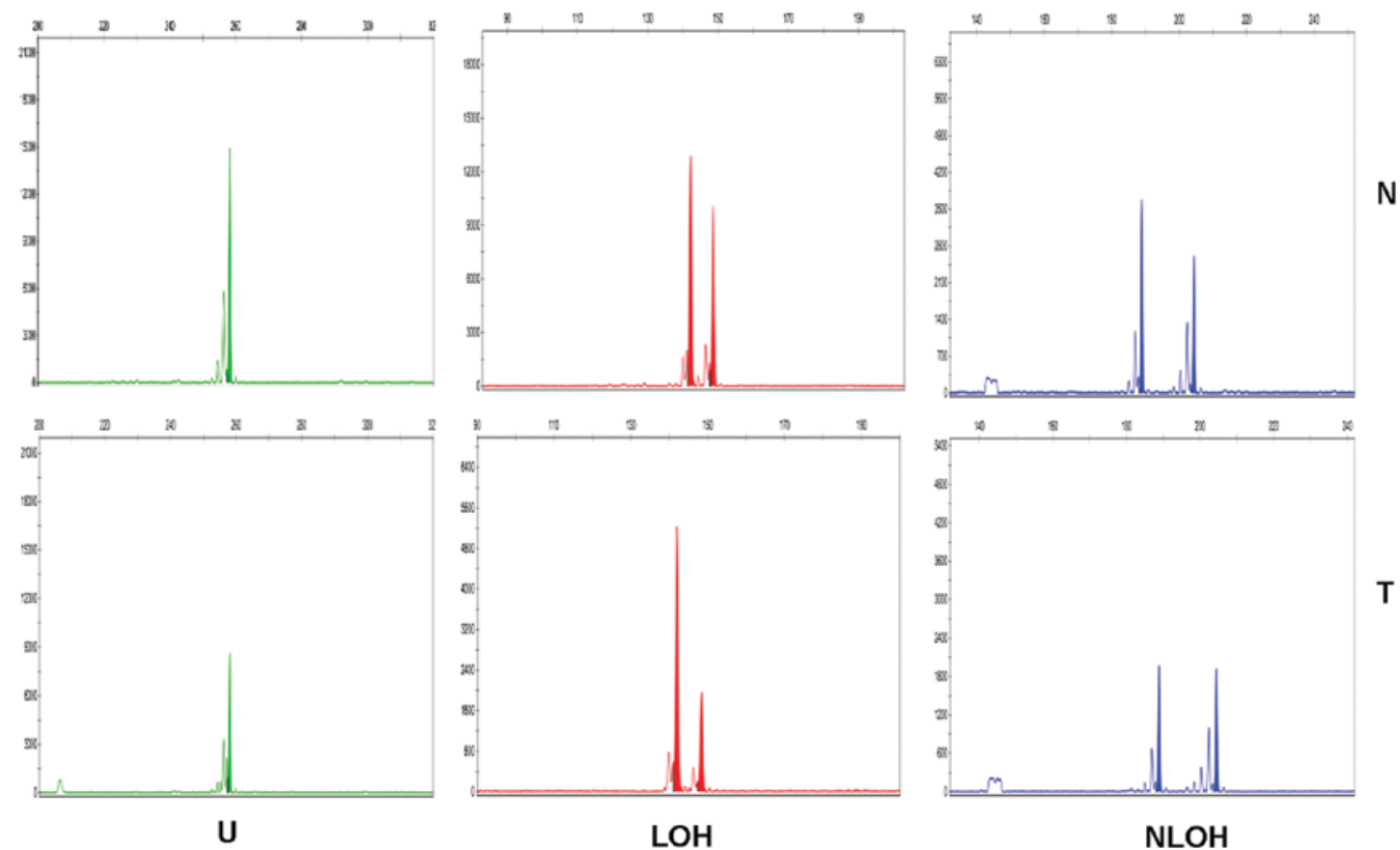

Figure 2. Representative capillary electrophoretic photographs for (A) SNP and (B) MS markers indicating LOH, non-LOH (NLOH) and uninformative (U) results in breast cancer. N, normal leucocyte DNA. T, tumor DNA. SNP, single-nucleotide polymorphism; MS, microsatellite; LOH, loss of heterogeneity.

four markers (Table IV). However, survival analysis revealed that breast cancer patients with LOH in the SNP marker rs2295283 had a poorer prognosis ( $\mathrm{P}=0.035)$ (Fig. 3; Table V). A similar trend was observed for MS loci, with an association with overall survival reaching significance $(\mathrm{P}=0.054)($ Table $\mathrm{V})$.

Additionally, we analyzed the correlations among the four MS/SNP markers and MIIP expression, and found MIIP expression was not affected by LOH status in the MIIP gene (Table VI).

\section{Discussion}

Cell motility and cell cycle regulation are essential processes for normal tissue development and remodeling. Disruption
Table III. Summary of LOH analysis of MIIP gene locus in 149 breast cancer cases using SNP and MS markers.

\begin{tabular}{lcr}
\hline Loci & $\begin{array}{c}\text { Informative samples/ } \\
\text { total }(\%)\end{array}$ & $\begin{array}{c}\text { LOH per informative } \\
\text { sample }(\%)\end{array}$ \\
\hline rs2295283 & $84 / 149(56.38)$ & $9 / 84(10.71)$ \\
D1S2740 & $70 / 149(46.98)$ & $14 / 70(20.00)$ \\
D1S489 & $97 / 149(65.10)$ & $20 / 97(20.62)$ \\
D1S434 & $97 / 149(65.10)$ & $16 / 97(16.49)$ \\
Overall MS loci & $138 / 149(92.62)$ & $33 / 138(23.91)$
\end{tabular}

LOH, loss of heterogeneity; MS, microsatellite; SNP, single-nucleotide polymorphism; MIIP, migration and invasion inhibitory protein. 
Table IV. Association between the MIIP gene LOH and clinicopathological characteristics in breast cancer patients.

\begin{tabular}{|c|c|c|c|c|c|c|c|c|c|c|c|c|c|c|c|}
\hline \multirow[b]{2}{*}{ Variables } & \multicolumn{3}{|c|}{ rs2295283 } & \multicolumn{3}{|c|}{$\mathrm{D} 1 \mathrm{~S} 2740$} & \multicolumn{3}{|c|}{ D1S489 } & \multicolumn{3}{|c|}{ D1S434 } & \multicolumn{3}{|c|}{ Overall MS loci } \\
\hline & - & + & $\mathrm{P}$-value & - & + & $\mathrm{P}$-value & - & + & P-value & - & + & $\mathrm{P}$-value & - & + & $\mathrm{P}$-value \\
\hline \multicolumn{16}{|l|}{ Age (years) } \\
\hline$\leq 50$ & 39 & 3 & 0.483 & 24 & 5 & 0.627 & 40 & 8 & 0.341 & 35 & 7 & 0.968 & 47 & 15 & 0.944 \\
\hline$>50$ & 36 & 6 & & 32 & 9 & & 37 & 12 & & 46 & 9 & & 58 & 18 & \\
\hline \multicolumn{16}{|l|}{ ER } \\
\hline- & 28 & 2 & 0.480 & 27 & 7 & 0.905 & 33 & 5 & 0.145 & 32 & 7 & 0.752 & 46 & 12 & 0.450 \\
\hline+ & 47 & 7 & & 29 & 7 & & 44 & 15 & & 49 & 9 & & 59 & 21 & \\
\hline \multicolumn{16}{|l|}{ PR } \\
\hline- & 28 & 4 & 0.726 & 26 & 7 & 0.811 & 30 & 7 & 0.745 & 31 & 6 & 0.954 & 45 & 14 & 0.965 \\
\hline+ & 47 & 5 & & 30 & 7 & & 47 & 13 & & 50 & 10 & & 60 & 19 & \\
\hline \multicolumn{16}{|l|}{$\begin{array}{l}\text { Benign breast } \\
\text { disease }\end{array}$} \\
\hline Never & 57 & 8 & 0.677 & 38 & 10 & 1.000 & 59 & 18 & 0.550 & 62 & 13 & 1.000 & 80 & 25 & 0.959 \\
\hline Ever & 18 & 1 & & 18 & 4 & & 17 & 3 & & 19 & 6 & & 25 & 8 & \\
\hline \multicolumn{16}{|l|}{$\begin{array}{l}\text { Family history } \\
\text { of cancer }\end{array}$} \\
\hline No & 44 & 6 & 0.733 & 39 & 8 & 0.525 & 51 & 11 & 0.351 & 52 & 8 & 0.258 & 71 & 17 & 0.080 \\
\hline Yes & 31 & 3 & & 17 & 6 & & 26 & 9 & & 28 & 8 & & 33 & 16 & \\
\hline \multicolumn{16}{|l|}{ Morphology } \\
\hline Non-invasive & 56 & 7 & 1.000 & 39 & 11 & 0.742 & 59 & 5 & 1.000 & 62 & 11 & 0.533 & 26 & 10 & 0.527 \\
\hline Invasive & 19 & 2 & & 17 & 3 & & 18 & 15 & & 19 & 5 & & 79 & 23 & \\
\hline \multicolumn{16}{|l|}{ Clinical stage } \\
\hline $0+\mathrm{I}$ & 39 & 2 & 0.091 & 32 & 10 & 0.329 & 39 & 11 & 0.729 & 43 & 12 & 0.106 & 56 & 22 & 0.178 \\
\hline $\mathrm{II}+\mathrm{III}$ & 36 & 7 & & 24 & 4 & & 38 & 9 & & 38 & 4 & & 49 & 11 & \\
\hline \multicolumn{16}{|c|}{ Tumor size (cm) } \\
\hline$\leq 2$ & 15 & 0 & 0.352 & 10 & 4 & 0.457 & 15 & 2 & 0.511 & 14 & 6 & 0.091 & 17 & 8 & 0.295 \\
\hline$>2$ & 60 & 9 & & 46 & 10 & & 62 & 18 & & 67 & 10 & & 88 & 25 & \\
\hline \multicolumn{16}{|l|}{$\begin{array}{l}\text { Lymph node } \\
\text { metastasis }\end{array}$} \\
\hline No & 36 & 2 & 0.174 & 30 & 10 & 0.227 & 34 & 12 & 0.206 & 43 & 11 & 0.249 & 55 & 21 & 0.257 \\
\hline Yes & 39 & 7 & & 26 & 4 & & 43 & 8 & & 38 & 5 & & 50 & 12 & \\
\hline
\end{tabular}

-, non-LOH (NLOH); +, LOH; MIIP, migration and invasion inhibitory protein; ER, estrogen receptor; PR, progesterone receptor; LOH, loss of heterogeneity.

of this homeostasis is involved in tumorigenesis and tumor progression through aberrant increase in cell migration and invasion as well as the loss of control for the cell cycle checkpoint. leading to genome instability (17). MIIP, as a novel candidate tumor suppressor, inhibits tumor cell migration and invasion and regulates mitosis through the IGFBP2 and histone deacetylase 6 (HDAC6) downstream target proteins (7). Song et al (6) first reported a significantly reduced MIIP expression in highly-invasive glioblastoma multiformes compared with normal brain and anaplastic glioma tissues. Subsequently, Wu et al (18) found a decrease in expression of MIIP in high-grade compared to lower-grade gliomas. Similarly, in the present study, we detected a decreased MIIP expression at the mRNA and protein level. This downregulation is more evident in patients with advanced tumor stage and larger tumor size. Therefore, MIIP may be important in the tumorigenic process and in the tumor development of breast cancer.

Although not fully elucidated, the mechanism by which MIIP is downregulated in tumors was examined in the present study. Considering its localization on chromosome 1p36 (refined in 1p36.22) where frequent deletions are observed in various cancer types (5), we hypothesized that attenuation of the MIIP gene is a genetic event contributing to carcinogenicity. However, this hypothesis was not further supported by the mutation screening of 59 glioma samples and pancreatic cancer tissues and cell lines, among which only rare frequent mutations were observed in the MIIP gene $(6,10)$. This observation suggests that MIIP may not be a classic TSG such as p53. In the present study, we provide evidence that MIIP 
Table V. Univariate analysis for overall survival of breast cancer patients.

\begin{tabular}{lccc}
\hline & \multicolumn{2}{c}{ Survival times (months) } & \\
\cline { 2 - 3 } Loci & Means & $95 \%$ CI & P-value \\
\hline rs2295283 & & & \\
- & 50.73 & $48.92-52.54$ & 0.035 \\
+ & 42.15 & $34.37-49.93$ & \\
D1S2740 & & & \\
- & 46.30 & $42.25-50.34$ & 0.286 \\
+ & 36.16 & $25.90-46.42$ & \\
D1S489 & & & 0.436 \\
- & 49.75 & $46.49-53.02$ & \\
+ & 48.64 & $43.33-53.95$ & \\
D1S434 & & & 0.782 \\
- & 44.87 & $40.87-48.87$ & \\
+ & 45.48 & $38.44-52.53$ & \\
Overall MS loci & & & \\
- & 50.09 & $48.21-51.96$ & 0.054 \\
+ & 46.02 & $40.47-51.59$ & \\
\hline
\end{tabular}

-, non-LOH $(\mathrm{NLOH}) ;+$, LOH; MS, microsatellite; LOH, loss of heterogeneity.

functions as a TSG in another important manner, similar to the CHD5 and PTEN genes whose inactivation occurs, not because of mutations but due to haploinsufficiency or the loss of one allele $(11,12)$.

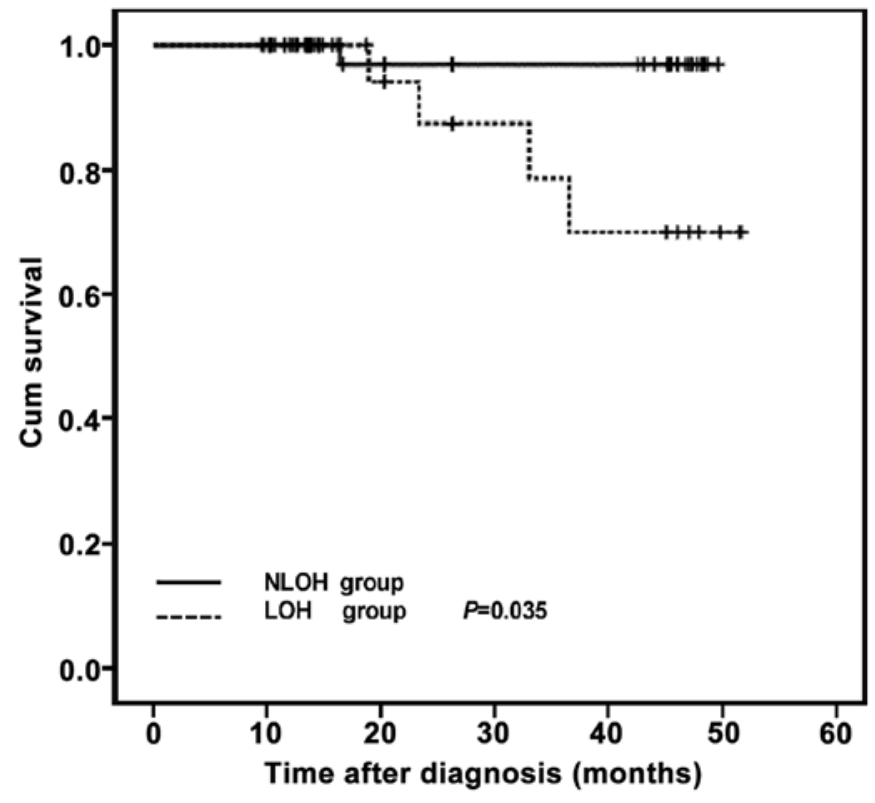

Figure 3. Kaplan-Meier curves of overall survival in breast cancer by the LOH status of MIIP SNP rs2295283. P-value is from the log-rank test. MIIP, migration and invasion inhibitory protein; SNP, single-nucleotide polymorphism; MIIP, migration and invasion inhibitory protein; LOH, loss of heterogeneity.

Frequent $\mathrm{LOH}$ of a specific chromosomal region is regarded as an indicator of a loss of a closely linked TSG. The classic method for LOH analysis is using MS markers. For its low coverage and uneven distribution on the chromosome, MS loci selected are usually distant from the relevant genes with poor representativeness (19). However, this method is prone to false-negative (such as non-symmetrical amplification

Table VI. Relationship between the LOH status and mRNA/protein expression of MIIP gene in breast cancer.

\begin{tabular}{|c|c|c|c|c|}
\hline & mRNA expression & & Protein expression & \\
\hline Loci & High expression/total (\%) & P-value & Median (min-max) & $\mathrm{P}$-value \\
\hline \multicolumn{5}{|c|}{ rs2295283 } \\
\hline- & $16 / 40(0.40)$ & \multirow[t]{2}{*}{0.454} & $20.05(0.95-63.04)$ & \multirow[t]{2}{*}{0.424} \\
\hline+ & $2 / 49(0.22)$ & & $14.35(4.04-56.67)$ & \\
\hline \multicolumn{5}{|c|}{ D1S2740 } \\
\hline- & $14 / 27(0.52)$ & \multirow[t]{2}{*}{0.564} & $20.12(1.68-40.73)$ & \multirow[t]{2}{*}{0.414} \\
\hline+ & $8 / 13(0.62)$ & & $22.78(3.51-63.04)$ & \\
\hline \multicolumn{5}{|c|}{ D1S489 } \\
\hline- & $17 / 42(0.41)$ & \multirow[t]{2}{*}{0.788} & $16.61(0.95-54.24)$ & \multirow[t]{2}{*}{0.599} \\
\hline+ & $7 / 19(0.37)$ & & $16.80(3.81-63.04)$ & \\
\hline \multicolumn{5}{|c|}{ D1S484 } \\
\hline- & $19 / 42(0.45)$ & \multirow[t]{2}{*}{0.919} & $16.61(0.95-63.45)$ & \multirow[t]{2}{*}{0.470} \\
\hline+ & $7 / 16(0.42)$ & & $16.99(3.51-63.04)$ & \\
\hline \multicolumn{5}{|c|}{ Overall MS loci } \\
\hline- & $16 / 45(0.36)$ & \multirow[t]{2}{*}{0.541} & $19.04(0.95-63.45)$ & \multirow[t]{2}{*}{0.877} \\
\hline+ & $16 / 38(0.42)$ & & $16.23(3.51-63.04)$ & \\
\hline
\end{tabular}


phenomenon) and false-positive (such as sliding) products, affecting the determination of the results (19). SNPs are the most common and widely distributed sequence variations in the human genome. Thus, LOH status of certain SNP may be the specifically localized gene itself $(15,19)$ and has been analyzed by many studies on other specific chromosomal loci $(14,20,21)$.

In the present study, we selected one intragenic SNP (rs2295283) (9) and the three nearest MS loci flanking the MIIP gene (D1S2740,DIS489 and D1S434) to evaluate the LOH of the MIIP gene. In our series of 142 informative samples of paired breast tumors and normal genomic DNA counterparts, we identified 37 tumors $(26 \%)$ showing $\mathrm{LOH}$, which clearly showed the allelic loss of one or more polymorphic sites within and close to the MIIP sequences. Furthermore, a significant association of allelic loss of MIIP with unfavorable overall survival in breast cancer cases was observed, strengthening the potential role of the locus in the development or progression of the breast tumors. No correlation was identified between MIIP downregulation and $\mathrm{LOH}$, suggesting there may be other to-be-determined mechanisms inactivating MIIP in breast cancer, such as homozygous deletion and methylation.

In conclusion, we present direct evidence that the MIIP sequences are susceptible to $\mathrm{LOH}$ in breast cancer, and suggested a possible association between this gene and development or progression of this disease. We cannot exclude the possibility of other candidate TSGs on chromosome 1p36 as potential LOH targets in breast cancer, Nevertheless, the occurrence of allelic deletion in the MIIP gene and loss of the gene expression in breast tumors presented in this study are useful for further functional and clinical exploration of this gene in cancer.

\section{Acknowledgements}

We would like to thank Hongwei Han and Lei Lei for their technical assistance. The Tissue Bank is jointly supported by the Tianjin Cancer Institute and Hospital, and the National Foundation for Cancer Research (USA). This study was supported by grants from the Specialized Research Fund for the Doctoral Program of Higher Education (no. 20101202120007), the National Natural Science Foundation of China (nos. 81172762 and 81302293), and the the Chinese 863 Program (no. 2012AA02A207).

\section{References}

1. Parkin DM, Bray F, Ferlay J and Pisani P: Global cancer statistics, 2002. CA Cancer J Clin 55: 74-108, 2005.

2. Wooster R, Bignell G, Lancaster J, Swift S, Seal S, Mangion J, Collins N, Gregory S, Gumbs C and Micklem G: Identification of the breast cancer susceptibility gene BRCA2. Nature 378: 789-792, 1995

3. Guan Y, Hata N, Kuga D, Yoshimoto K, Mizoguchi M, Shono T, Suzuki SO, Tahira T, Kukita Y, Higasa K, et al: Narrowing of the regions of allelic losses of chromosome 1p36 in meningioma tissues by an improved SSCP analysis. Int J Cancer 122: 1820-1826, 2008.
4. Zwahlen D, Tschan MP, Grob TJ, Peters UR, Fink D, Haenggi W, Altermatt HJ, Cajot JF, Tobler A, Fey MF, et al: Differential expression of p73 splice variants and protein in benign and malignant ovarian tumours. Int J Cancer 88: 66-70, 2000.

5. Song SW, Fuller GN, Zheng H and Zhang W: Inactivation of the invasion inhibitory gene IIp45 by alternative splicing in gliomas. Cancer Res 65: 3562-3567, 2005.

6. Song SW, Fuller GN, Khan A, Kong S, Shen W, Taylor E, Ramdas L, Lang FF and Zhang W: IIp45, an insulin-like growth factor binding protein 2 (IGFBP-2) binding protein, antagonizes IGFBP-2 stimulation of glioma cell invasion. Proc Natl Acad Sci USA 100: 13970-13975, 2003.

7. Wang Y, Wen J and Zhang W: MIIP, a cytoskeleton regulator that blocks cell migration and invasion, delays mitosis, and suppresses tumorogenesis. Curr Protein Pept Sci 12: 68-73, 2011.

8. Ji P, Smith SM, Wang Y, Jiang R, Song SW, Li B, Sawaya R, Bruner JM, Kuang J, Yu H, et al: Inhibition of gliomagenesis and attenuation of mitotic transition by MIIP. Oncogene 29: 3501-3508, 2010.

9. Song F, Ji P, Zheng H, Song F, Wang Y, Hao X, Wei Q, Zhang W and Chen K: Definition of a functional single nucleotide polymorphism in the cell migration inhibitory gene MIIP that affects the risk of breast cancer. Cancer Res 70: 1024-1032, 2010.

10. Wang Y, Yang D, Cogdell D, Hu L, Xue F, Broaddus R and Zhang W: Genomic characterization of gene copy-number aberrations in endometrial carcinoma cell lines derived from endometrioid-type endometrial adenocarcinoma. Technol Cancer Res Treat 9: 179-189, 2010.

11. Cairns P, Evron E, Okami K, Halachmi N, Esteller M, Herman JG, Bose S, Wang SI, Parsons R and Sidransky D: Point mutation and homozygous deletion of PTEN/MMAC1 in primary bladder cancers. Oncogene 16: 3215-3218, 1998

12. Fujita T, Igarashi J, Okawa ER, Gotoh T, Manne J, Kolla V, Kim J, Zhao H, Pawel BR, London WB, et al: CHD5, a tumor suppressor gene deleted from $1 \mathrm{p} 36.31$ in neuroblastomas. J Natl Cancer Inst 100: 940-949, 2008.

13. Livak KJ and Schmittgen TD: Analysis of relative gene expression data using real-time quantitative PCR and the 2(-Delta Delta C(T)) method. Methods 25: 402-408, 2001.

14. Chosdol K, Misra A, Puri S, Srivastava T, Chattopadhyay P, Sarkar C, Mahapatra AK and Sinha S: Frequent loss of heterozygosity and altered expression of the candidate tumor suppressor gene 'FAT' in human astrocytic tumors. BMC Cancer 9: 5, 2009.

15. Schwarzenbach H, Muller V, Beeger C, Gottberg M, Stahmann N and Pantel K: A critical evaluation of loss of heterozygosity detected in tumor tissues, blood serum and bone marrow plasma from patients with breast cancer. Breast Cancer Res 9: R66, 2007.

16. Xu XM, Qian JC, Cai Z, Tang T, Wang P, Zhang KH, Deng ZL and Cai JP: DNA alterations of microsatellite DNA, p53, APC and K-ras in Chinese colorectal cancer patients. Eur J Clin Invest 42: 751-759, 2012.

17. Hanahan D and Weinberg RA: The hallmarks of cancer. Cell 100: $57-70,2000$.

18. Wu Y, Song SW, Sun J, Bruner JM, Fuller GN and Zhang W: IIp45 inhibits cell migration through inhibition of HDAC6. J Biol Chem 285: 3554-3560, 2010.

19. Hata N, Yoshimoto K, Yokoyama N, Mizoguchi M, Shono T, Guan Y, Tahira T, Kukita Y, Higasa K, Nagata S, et al: Allelic losses of chromosome 10 in glioma tissues detected by quantitative single-strand conformation polymorphism analysis. Clin Chem 52: 370-378, 2006.

20. Cvetkovic D, Pisarcik D, Lee C, Hamilton TC and Abdollahi A: Altered expression and loss of heterozygosity of the LOT1 gene in ovarian cancer. Gynecol Oncol 95: 449-455, 2004.

21. Wegman PP, Marcus NJ, Malakkaran BP and Wingren S: Biological significance of allele specific loss of the p53 gene in breast carcinomas. Breast Cancer Res Treat 118: 15-20, 2009. 